\title{
Antitussive effect of carcainium chloride in patients with chronic cough and idiopathic interstitial pneumonias: A pilot study
}

\author{
Federico Lavorini ${ }^{\text {a, }}{ }^{*}$, Domenico Spina ${ }^{b}$, Michael J. Walker ${ }^{c}$, Lui Franciosi ${ }^{\text {c }}$, Clive P. Page ${ }^{\text {b }}$, \\ Giovanni A. Fontana ${ }^{\text {a }}$ \\ ${ }^{a}$ Department of Experimental and Clinical Medicine, University of Florence, Italy \\ ${ }^{\mathrm{b}}$ Sackler Institute of Pulmonary Pharmacology, Institute of Pharmaceutical Science, King's College London, UK

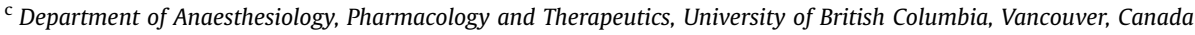

\section{A R T I C L E I N F O}

\section{Article history:}

Received 17 May 2016

Received in revised form

27 July 2016

Accepted 2 August 2016

Available online 15 August 2016

\section{Keywords:}

Cough

Carcainium chloride

Antitussive

Idiopathic interstitial pneumonia

\begin{abstract}
A B S T R A C T
Background: Cough is a common presenting symptom in patients with idiopathic interstitial pneumonia (IIP); it is often disabling, and lacks effective treatment. Studies in animals suggest that carcainium chloride, a quaternary derivative of the local anesthetic lidocaine, is able to inhibit experimentally induced cough by a mechanism of action distinct from that of lidocaine.

Objective: To determine the effectiveness of aerosolised carcainium chloride (VRP700) in controlling cough in patients with IIP.

Methods: Eight female patients (mean age 71 years) with IIP were investigated in a double blind, randomised, placebo controlled crossover, adaptive contingency study design (EudraCT Number 2010021350-19). The study consisted of a screening visit to assess the eligibility of patients, and two separated (48-72 h) study days. On the two study days, patients were randomised to receive either nebulized VRP700 $(1.0 \mathrm{mg} / \mathrm{kg})$ on the first study visit followed by nebulised placebo (sodium chloride $0.9 \%)$ on the second visit, or placebo on the first visit followed by VRP700 on the second visit. The primary endpoint was cough frequency over a 4-h assessment period; secondary endpoints were subjective cough-related level of discomfort as assessed by a visual analogue scale (VAS) and the subjective response to treatment as assessed by a quality of life question. Safety (ECG, spirometry, urine and blood tests) and adverse events occurring during the trial were also investigated.

Results: In all patients both VRP700 and placebo decreased cough frequency; however, mean decreases in cough frequency after treatment with VRP700 were significantly $(\mathrm{P}<0.001)$ higher than with placebo. Similarly, mean reductions in VAS score were significantly $(\mathrm{P}<0.001)$ higher after treatment with VRP 700 compared with placebo. All but one patient indicated that they felt better after receiving VRP700. No adverse events were reported during the study, nor were any changes in ECG variables, spirometry, urine and blood tests noted.

Conclusion: The results of this exploratory study indicate that nebulised VRP700 improved cough and quality of life in hospitalised IIP patients with no significant side effects. A larger trial is warranted to assess these promising results.
\end{abstract}

๑) 2016 Elsevier Ltd. All rights reserved.

\footnotetext{
Abbreviations: Cph, coughs per hour; IIP, idiopathic interstitial pneumonia; $\mathrm{C}_{\max }$, maximum plasma concentration; $\mathrm{T}_{\max }$, time to reach maximum plasma concentration; VAS, visual analogue scale.

* Corresponding author. Department of Experimental Medicine, Careggi University Hospital Largo Brambilla 2, 50134, Florence, Italy.

E-mail address: Federico.lavorini@unifi.it (F. Lavorini).
}

\section{Introduction}

Chronic cough remains a serious unmet medical need $[1,2]$. Cough is a nerve reflex involving the activation of vagally innervated receptors ultimately resulting in cough motor events [3]. Receptors (sensors) implicated in the cough reflex have been found on families of both thin myelinated $(\mathrm{A} \delta$ ) and unmyelinated bronchial and pulmonary $C$ sensory nerve fibres $[4,5]$ Not surprisingly, therefore, local anaesthetics can inhibit coughing presumably via 
inhibition of conduction of these sensory nerve fibers [6], but they are known to interfere with other important protective reflexes such as the gag reflex [7], limiting their wider use in the clinic.

Carcainium chloride, that is structurally related to the local anaesthetic lidocaine [8], has been reported to reduce cough responses in guinea pigs and rabbits by selective inhibition of A $\underline{\delta}$ fibres when applied topically to the airways, whilst having no inhibitory effect on bronchial or pulmonary C-fibres, which were both inhibited by topical lidocaine [9]. To our knowledge, this selectivity for A $\delta$ fibres has not been reported so far for other drug classes. However, to date no studies investigating the effect of inhaled carcainium chloride on cough responses have been reported in humans.

This pilot study, therefore, aimed to investigate the effectiveness of inhaled carcainium chloride (hereafter named VRP700) in controlling cough of patients with idiopathic interstitial pneumonia (IIP) [10]. Patients with IIPs were chosen since cough is a distressing and disabling symptom of this disease [10].

\section{Methods}

\subsection{Study design and participants}

This was a randomised, double blind, crossover, placebo controlled study performed according to an adaptive contingency design [11]. We enrolled adult, non-smoking inpatients with IIP and refractory chronic cough [12]. We excluded patients who reported $<1$ month respiratory tract infections, who were taking an angiotensin-converting enzyme inhibitor, or who had liver or renal dysfunction. Women breastfeeding or of childbearing age were also excluded. Written consent was obtained from each patient; the study was approved by the Ethics Committee of the Careggi Hospital (EudraCT number 2010-021350-19).

\subsection{Protocol and recording procedures}

After screening, each patient was examined on two separate (48-72 h) occasions (Fig. 1). On each occasion, patients randomly inhaled $1.0 \mathrm{mg} / \mathrm{kg}$ VRP700 or placebo (sodium chloride $0.9 \%$ ) by means of a DeVilbissUltraNeb 3000 nebuliser set to produce $2 \mathrm{~mL} /$ min of aerosol. Administration continued until nebulisation occurred; a $\sim 1.2 \mathrm{~mL}$ residue remained in the nebuliser cup after each nebulisation. After study completion, patients were followed up for a further $12-24 \mathrm{~h}$. On all occasions, the cough frequency was recorded at baseline and for $4 \mathrm{~h}$ after the completion of each inhalation period by means of a cough recorder (PulmoTrack ${ }^{\circledR} 2010$ W-Holter, Karmelsonic) [13] and expressed as coughs per hour (cph). Cough-related level of discomfort was investigated by a 10$\mathrm{cm}$ visual analogue scale (VAS), with the extremes indicating no discomfort $(0 \mathrm{~cm})$ or extreme discomfort $(10 \mathrm{~cm})$. Patients' subjective response to treatments was also assessed $4 \mathrm{~h}$ post treatment asking the patients: "how do you feel: worse, same or better following treatment?" Similarly, physicians' judgement (i.e. superior, same, inferior) of individual patient responses in terms of anti-tussive actions compared to baseline was also obtained. Vital signs, ECG and spirometry variables were recorded at baseline and 15, 20, 40, 60, 90, $120 \mathrm{~min}, 3$ and $4 \mathrm{~h}$ after drugs administration. Concomitant medication changes and adverse events were reported. Blood and urine samples were collected for standard safety laboratory assessments; blood samples were also taken at baseline, at 20, 40, 60, 90,120 min and 3, $4 \mathrm{~h}$ after VRP700 inhalation to calculate the maximum plasma concentration $\left(\mathrm{C}_{\max }\right)$ and time to reach $C_{\max }\left(\mathrm{T}_{\max }\right)[14]$.

\subsection{Data analysis}

The primary outcome variable was cough frequency over a 4-h assessment period measured before and after VRP700 and placebo administration; secondary outcome variables were VAS scores, patients' subjective response and physicians' judgement. Categorical data were expressed as percentages, whereas normal distributed data were presented as mean \pm SD. For efficacy parameters, all tests for a difference between the two treatments have been two-sided and performed at the $5 \%$ significance level.

\section{Results}

Eight female patients (Table 1) completed the study with no significant changes in vital signs, ECG variables, spirometry, as well as in any parameters measured in blood or urine. Preliminary CT scans indicated that six patients suffered from usual interstitial pneumonia, one had non-specific interstitial lung disease, and another one had an unclassifiable IIP. No patients reported adverse events during the study. However, they consistently coughed more during the 1st or 2nd minutes of nebulisation of active drug, followed by a marked decrease in cough over the rest of nebulisation period. As the cough monitor was not started until after inhalation had completed, these initial coughs have not been recorded.

In the patients as a group, $C_{\max }$ for VRP700 ranged from 2.26 to $37.7 \mathrm{ng} / \mathrm{mL}$ with a $\mathrm{T}_{\max }$ of $20 \mathrm{~min}$.

VRP700 significantly decreased cough frequency from $57.75 \pm 15.51 \mathrm{cph}$ to $13.13 \pm 9.62 \mathrm{cph} 4 \mathrm{~h}$ after VRP700 administration ( $\mathrm{p}<0.001$, Fig. 2 ). With placebo, the same variable decreased from $46.06 \pm 10.70 \mathrm{cph}$ to $37.38 \pm 19.34 \mathrm{cph}(\mathrm{NS})$.

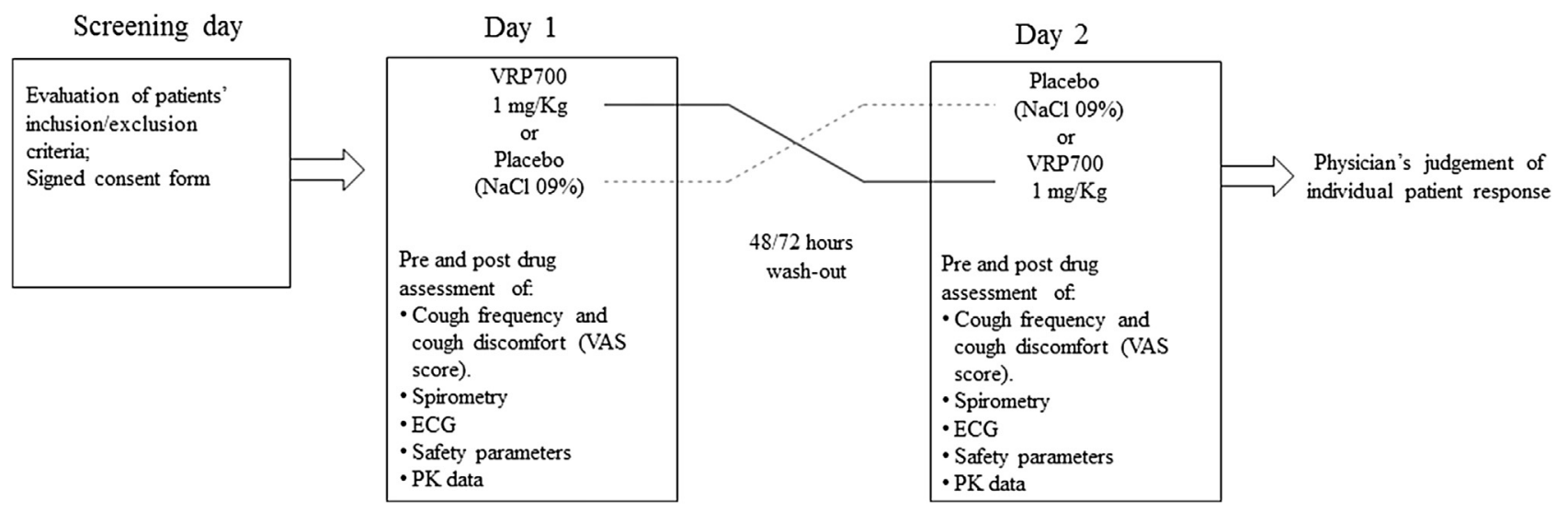

Fig. 1. Study flow chart. PK, pharmacokinetic; See text for details. 
Table 1

Patients "characteristics.

\begin{tabular}{|c|c|c|c|c|c|c|c|c|}
\hline Pt. no. & Sex & Age (years) & BMI & $\mathrm{FEV}_{1}$ (\% pred.) & FVC (\% pred.) & TLC (\% pred.) & $D_{\mathrm{L}} \mathrm{CO}$ (\% pred.) & Main ongoing treatment \\
\hline 1 & $\mathrm{~F}$ & 75 & 27.07 & 63 & 60 & 62 & 49 & OCS, PPI, N-ACC \\
\hline 2 & $\mathrm{~F}$ & 79 & 27.00 & NA & NA & NA & NA & OCS, PPI, N-ACC \\
\hline 3 & $\mathrm{~F}$ & 75 & 30.05 & 88 & 90 & 80 & 65 & PPI, N-ACC \\
\hline 4 & $\mathrm{~F}$ & 75 & 28.00 & 70 & 64 & 65 & 59 & OCS, PPI \\
\hline 5 & $\mathrm{~F}$ & 56 & 23.15 & 88 & 91 & 99 & 70 & OCS \\
\hline 6 & $\mathrm{~F}$ & 69 & 36.10 & 81 & 76 & 61 & 32 & OCS, PPI,Ox \\
\hline 7 & $\mathrm{~F}$ & 68 & 33.01 & 80 & 82 & 77 & 60 & OCS, PPI,Ox, N-ACC \\
\hline 8 & $\mathrm{~F}$ & 71 & 29.00 & 66 & 66 & 64 & 48 & \\
\hline Mean & - & 71.00 & 28.00 & 76.57 & 75.57 & 72.57 & 54.71 & \\
\hline SD & & 7.07 & 1.00 & 10.26 & 12.62 & 13.84 & 12.78 & \\
\hline
\end{tabular}

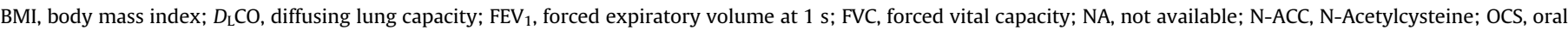
corticosteroids; Ox, oxygen; Pt, patient; PPI, proton pump inhibitors; pred, predicted value; TLC, total lung capacity.

Comparisons of mean decreases in cough frequency with VRP 700 and placebo demonstrated a much higher reduction $(P<0.001)$ in cough frequency with the active drug rather than with placebo (Fig. 1).

In all patients, VRP700 reduced $(\mathrm{P}<0.001)$ baseline VAS scores with an overall mean reduction of $5.60 \pm 0.90$. For the placebo treatment, in four patients the post-placebo values were lower than the pre-placebo values with an overall mean reduction of $1.8 \pm 1.0$
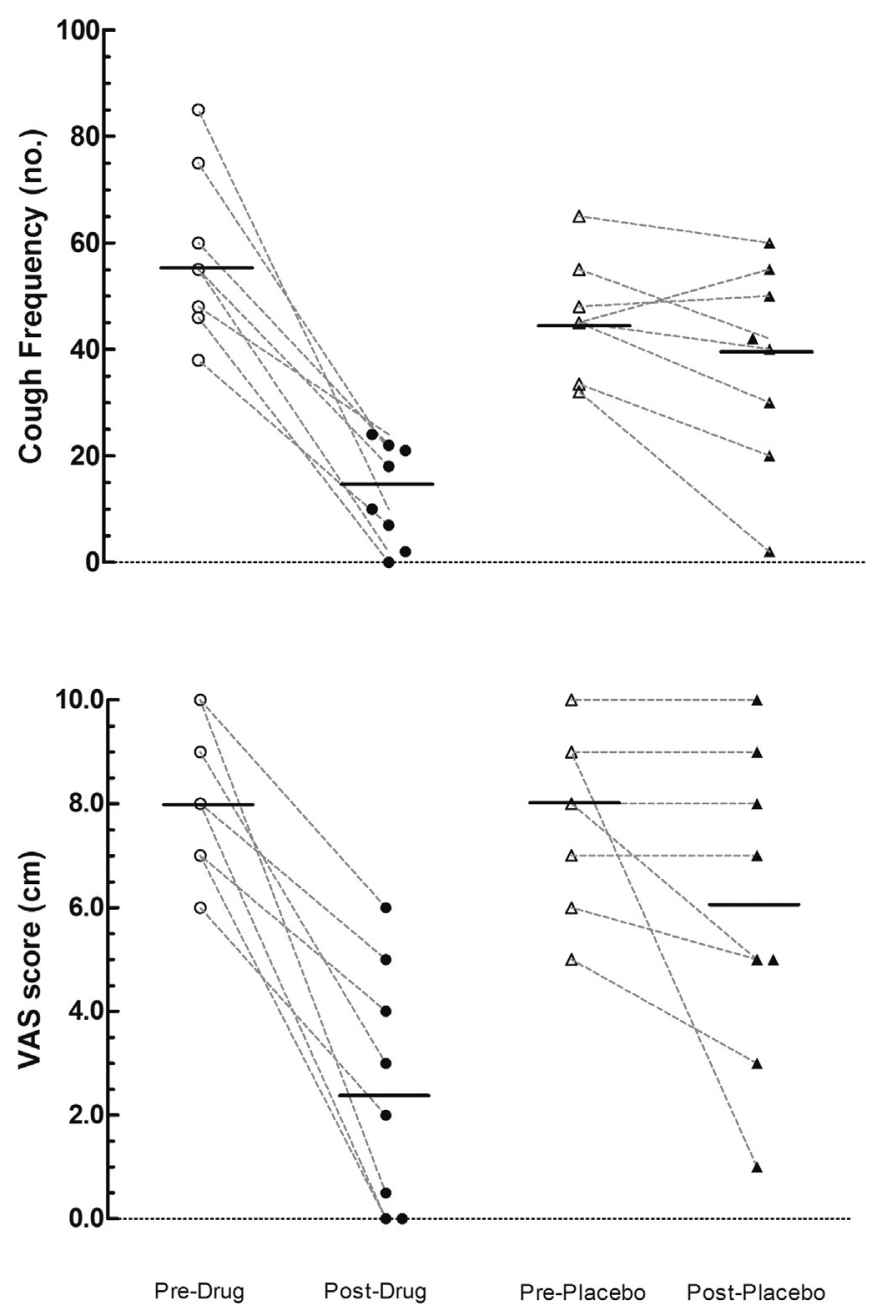

Fig. 2. Individual values of cough frequency (upper panel) and visual analogue scale (VAS) score (lower panel) recorded pre and post drug or placebo administration. Bars represent median values.
(Fig. 2). As with cough frequency, comparisons of mean changes in VAS score with VRP 700 and placebo demonstrated a significantly $(\mathrm{P}<0.001)$ higher reduction in VAS score with the active drug rather than with placebo (Fig. 2). Scrutiny of data (Fig. 2) indicated that in 4 patients treated with the sequence VRP700-placebo, the cough frequency values and VAS scores were smaller after placebo than after the reverse sequence.

All patients indicated that they felt better after receiving VRP700. Only 1 patient felt better after receiving placebo and one felt worse: the remaining patient reported no appreciable change; so that the difference between the 2 treatments was statistically significant $(\mathrm{P}<0.02$ by Chi squared). In all patients, physicians selected VRP700 as being the more effective $(P<0.01)$ treatment in reducing the patient's cough frequency.

\section{Discussion}

We have demonstrated a marked antitussive effect of nebulised VRP700 in patients with chronic cough and IIP with an overall $80 \%$ reduction in cough frequency. Patients also reported a remarkable subjective improvement, also confirmed by medical evaluation. VRP700 appears to be safe since none of the patients reported any clinically relevant side effect, notably no paraesthesia that has been reported following treatment with local anaesthetics.

One limitation of the crossover study design is the so-called carry over effect [15]. Indeed, four patients showed a larger reduction in cough frequency and VAS score when they received the sequence VRP700-placebo rather than the sequence placeboVRP700, thus suggesting that prior exposure to the active drug may have enhanced the subsequent responses to placebo. However, overall, the active drug proved to be far more effective than placebo in the patients as a group, although there were insufficient samples to test for statistical significance of the sequence effect in the study population. On the other hand, the advantage of the statistical method used here [11] is that it does not require an initial commitment to a large sample size, since the ultimate sample size was determined by the data generated during the study.

The reason for female patients being studied reflected that patient recruitment was consecutive, and the greater severity of the disease in females [16] may have contributed.

The exact mechanism(s) underlying cough in IIP remains unclear [17]. For instance, more than $50 \%$ of patients with interstitial lung disease could have cough caused by other causes such as asthma, rhinitis or gastro-oesophageal reflux [18,19]. However, IIP may directly cause cough as inflammation is not limited to the parenchyma, and disrupted airway epithelium [20] with inflammatory mediators known to provoke cough having been detected in such patients $[17,18]$. A further possible cause of cough in 
patients with IIP is airway distortion secondary to interstitial fibrosis, which results in traction bronchiectasis [21].

Whilst the molecular mechanism of action of VRP700 remains incompletely understood, this is highly unlikely to be due to any local anaesthetic activity of this drug as it has a distinct electrophysiological profile from lidocaine on airway sensory nerves [9]. In addition, VRP700 inhibits the activation of airway A $\delta$ fibres selectively [9], a finding in keeping with a major role for A $\underline{\delta}$ fibres in many patients with chronic cough.

The antitussive effect of VRP700 is comparable to that recently reported using a P2X3 purinergic receptor antagonist (AF-219) in patients with refractory chronic cough [22]. However, unlike AF219 , which was associated with loss of taste in the majority of patients, VRP700 was not associated with any major side effects.

In conclusion, VRP700 may be promising and safe in patients with IIP. Whether the drug is also suitable for long-term administration and in the management of patients with intractable cough of different origin remains to be ascertained.

\section{Funding sources}

This research did not receive any specific grant from funding agencies in the public, commercial, or not-for-profit sectors. However, the authors acknowledge the kind gift of VRP 700 from Verona Pharma, London, UK.

\section{Conflict of interest statement}

MJW and LF are former employees of Verona Pharma. CPP, LF and MJW have equity in Verona Pharma and DS is a former consultant and has received grants from Verona Pharma. FL and GF declare no conflict of interest related to this work.

\section{References}

[1] W.J. Song, Y.S. Chang, S. Faruqi, J.Y. Kim, M.G. Kang, S. Kim, E.J. Jo, M.H. Kim, J. Plevkova, H.W. Park, S.H. Cho, A.H. Morice, The global epidemiology of chronic cough in adults: a systematic review and meta-analysis, Eur. Respir. J. 45 (2015) 1479-1481.

[2] P.G. Gibson, A.E. Vertigan, Management of chronic refractory cough, BMJ 351 (2015) 5590.

[3] J. Widdicombe, G. Fontana, Cough: what's in a name? Eur. Respir. J. 28 (2006) $10-15$.

[4] J. Widdicombe, V. Singh, Physiological and pathophysiological downregulation of cough, Respir. Physiol. Neurobiol. 150 (2006) 105-117.
[5] D. Spina, C.P. Page, Regulating cough through modulation of sensory nerve function in the airways, Pulm. Pharmacol. Ther. 26 (2013) 486-490.

[6] J.A. Karlsson, Airway anaesthesia and the cough reflex, Bull. Eur. Physiopathol. Respir. 23 (1) (1987) 29s-36s.

[7] K.G. Lim, M.A. Rank, P.Y. Hahn, K.A. Keogh, T.I. Morgenthaler, E.J. Olson, Longterm safety of nebulized lidocaine for adults with difficult-to-control chronic cough: a case series, Chest 143 (2013) 1060-1065.

[8] H.E. D'Amato, A.P. Truant, Antiarrhythmic activity of a series of quaternary derivatives of lidocaine, Fed. Proc. 21 (1962) 127.

[9] J.J. Adcock, G.J. Douglas, M. Garabette, M. Gascoigne, G. Beatch, M. Walker, C.P. Page, RSD931, a novel anti-tussive agent acting on airway sensory nerves, Br. J. Pharmacol. 138 (2003) 407-416.

[10] W.D. Travis, U. Costabel, D.M. Hansell, T.E. King Jr., D.A. Lynch, A.G. Nicholson, C.J. Ryerson, J.H. Ryu, M. Selman, A.U. Wells, J. Behr, D. Bouros, K.K. Brown, T.V. Colby, H.R. Collard, C.R. Cordeiro, V. Cottin, B. Crestani, M. Drent, R.F. Dudden, J. Egan, K. Flaherty, C. Hogaboam, Y. Inoue, T. Johkoh, D.S. Kim, M. Kitaichi, J. Loyd, F.J. Martinez, J. Myers, S. Protzko, G. Raghu, L. Richeldi, N. Sverzellati, J. Swigris, D. Valeyre, ATS/ERS committee on idiopathic interstitial pneumonias. An official american thoracic society/european respiratory society statement: update of the international multidisciplinary classification of the idiopathic interstitial pneumonias, Am. J. Respir. Crit. Care Med. 188 (2013) 733-748.

[11] S.A. Murphy, An experimental design for the development of adaptive treatment strategies, Stat. Med. 24 (2005) 1455-1481.

[12] A.H. Morice, G.A. Fontana, M.G. Belvisi, S.S. Birring, K.F. Chung, P.V. Dicpinigaitis, J.A. Kastelik, L.P. McGarvey, J.A. Smith, M. Tatar, J. Widdicombe, European Respiratory Society guidelines on the assessment of cough, Eur. Respir. J. 29 (2007) 1256-1276.

[13] E. Vizel, M. Yigla, Y. Goryachev, E. Dekel, V. Felis, H. Levi, I. Kroin, S. Godfrey, N. Gavriely, Validation of an ambulatory cough detection and counting application using voluntary cough under different conditions, Cough 6 (2010) 3.

[14] J.J. Pitt, Principles and applications of liquid chromatography-mass spectrometry, Clin. Biochem. Rev. 30 (2009) 19-34.

[15] M.E. Putt, Power to detect clinically relevant carry-over in a series of crossover studies, Stat. Med. 25 (2006) 2567-2586.

[16] Olson AL1, J.J. Swigris, D.C. Lezotte, J.M. Norris, C.G. Wilson, Brown KK.Mortality from pulmonary fibrosis increased in the United States from 1992 to 2003, Am. J. Respir. Crit. Care Med. 176 (2007) 277-284.

[17] N.K. Harrison, Idiopathic pulmonary fibrosis: a nervous cough? Pulm. Pharmacol. Ther. 174 (2004) 347-350.

[18] J.M. Madison, R.S. Irwin, Chronic cough in adults with interstitial lung disease, Curr. Opin. Pulm. Med. 11 (2005) 412-416.

[19] Kilduff CE, Counter MJ, Thomas GA, Harrison NK, Hope-Gill BD. Effect of acid suppression therapy on gastroesophageal reflux and cough in idiopathic pulmonary fibrosis: an intervention study. Cough 10 (214) 4.

[20] M.J. Doherty, R. Mister, M.G. Pearson, P.M. Calverley, Capsaicin induced cough in cryptogenic fibrosing alveolitis, Thorax 55 (2000) 1028-1032.

[21] R.M. Jones, S. Hilldrup, B.D. Hope-Gill, R. Eccles, N.K. Harrison, Mechanical induction of cough in idiopathic pulmonary fibrosis, Cough 7 (2011) 2.

[22] R. Abdulqawi, R. Dockry, K. Holt, G. Layton, B.G. McCarthy, A.P. Ford, J.A. Smith, P2X3 receptor antagonist (AF-219) in refractory chronic cough: a randomised, double-blind, placebo-controlled phase 2 study, Lancet 385 (2015) 1198-1205. 